\title{
Spontaneous Healing of a Displaced Bucket-Handle Tear of the Lateral Meniscus in a Child
}

\author{
Jae Hwi Han, $\mathrm{MD}^{1}$, Jae Gwang Song, $\mathrm{MD}^{1}$, Jae Ho Kwon, $\mathrm{MD}^{2}$, Kyung Woon Kang, $\mathrm{MD}^{1}$, Daviesh Shah, $\mathrm{MS}^{1}$, \\ and Kyung-Wook Nha, $\mathrm{MD}^{1}$ \\ ${ }^{1}$ Department of Orthopaedic Surgery, Inje University Ilsan Paik Hospital, Ilsan; ${ }^{2}$ Department of Orthopaedic Surgery, Barunsesang Hospital, Bundang, Korea
}

Bucket-handle tears less frequently occur in the lateral meniscus than in the medial meniscus. An 11-year-old male patient complained of painful swelling and locking due to a displaced bucket-handle tear of the lateral meniscus. We recommended an arthroscopic surgery; however, the patient left the hospital without surgical treatment. Six weeks afterwards, he returned without any complain of pain and he regained full range of motion. The final follow-up magnetic resonance imaging showed reduction of the torn meniscal fragment without any signal changes suggestive of a meniscal tear. We report a rare case of an isolated displaced bucket-handle tear of the lateral meniscus in an 11-year-old patient that healed spontaneously without surgical intervention.

Keywords: Knee, Lateral meniscus, Bucket-handle tear, Child

Meniscal tears less frequently occur in young patients under the age of 18 years $^{11}$. Bucket-handle tears take approximately $10 \%$ of all meniscal tears, and medial meniscal tears are three times more common than lateral tears ${ }^{2)}$. However, the lateral meniscus is relatively loosely attached to the capsule that is interrupted by the popliteal hiatus, which allows it to be quite mobile. Therefore, the posterior horn of the lateral meniscus is susceptible to subluxation resulting in a displaced bucket handle tear ${ }^{3,4}$. We report a rare case of a child with a displaced bucket-handle tear of the lateral meniscus in the stable knee that healed spontaneously without any surgical procedures.

Received June 27, 2014; Revised September 2, 2014;

Accepted October 10, 2014

Correspondence to: Kyung-Wook Nha, MD

Department of Orthopaedic Surgery, Inje University Ilsan Paik Hospital, 170 Juhwa-ro, Ilsanseo-gu, Goyang 411-706, Korea

Tel: +82-31-910-7312, Fax: +82-31-910-7319

E-mail:kwnhamj@hotmail.com

This is an Open Access article distributed under the terms of the Creative Commons Attribution Non-Commercial License (http://creativecommons.org/licenses/by-nc/3.0/) which permits unrestricted non-commercial use, distribution, and reproduction in any medium, provided the original work is properly cited.

\section{Case Report}

An 11-year-old male patient presented to our hospital with painful swelling on his right knee. He felt pain after a twisting injury inflicted during a soccer game 3 days ago. On physical examination, there was tenderness on the lateral joint line with a limited motion of $20^{\circ}$ to $90^{\circ}$ flexion. He was unable to perform full extension of his knee due to locking. McMurray's test could not be performed. Aspiration of the knee yielded $20 \mathrm{~mL}$ of bloody fluid. Magnetic resonance imaging (MRI) showed a bucket-handle tear of the lateral meniscus with no other abnormal findings (Fig. 1). The patient was recommended for an arthroscopic surgery, but the patient was lost to contact. Six weeks afterwards, the patient and his parents re-visited the hospital to discuss the operation. He reported that he had removed the splint at the end of the first week by himself due to discomfort, but he had not felt any pain without it. On physical examination, limping gait and swelling were not observed. He was free of pain and recovered full range of motion. Tenderness and McMurray's test were negative. In the periodic follow-up, he was free of symptoms. At 18 months of follow-up, MRI showed reduction of the torn meniscal fragment without any signal changes suggestive of the meniscal tear (Fig. 2). At the final follow-up, 18 months later, the patient was free of symptoms. He had no giving way or sub- 

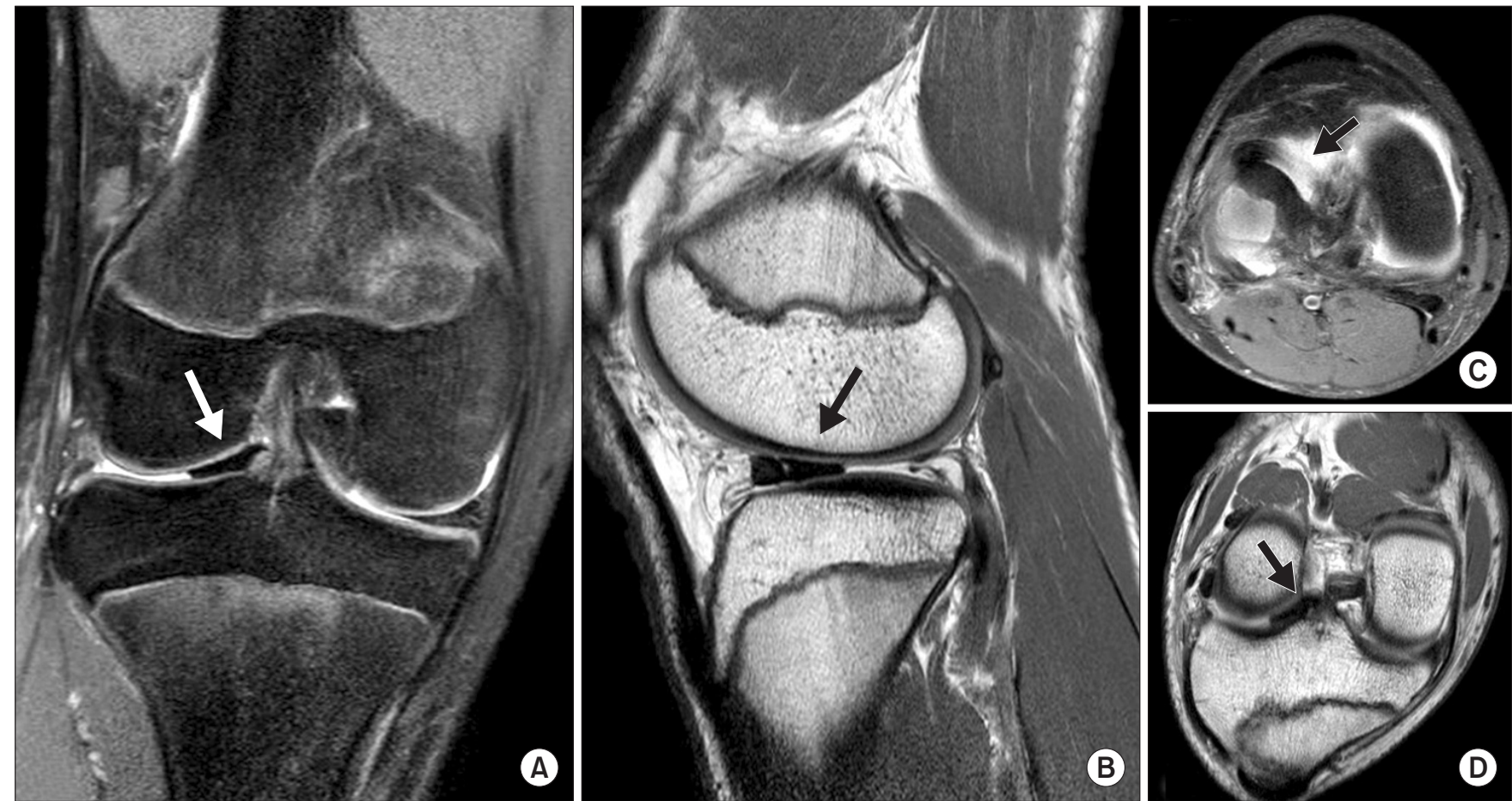

Fig. 1. Initial coronal (A), sagittal (B), axial (C), and oblique (D) magnetic resonance images showing a displaced bucket-handle tear of the lateral meniscus (arrows).
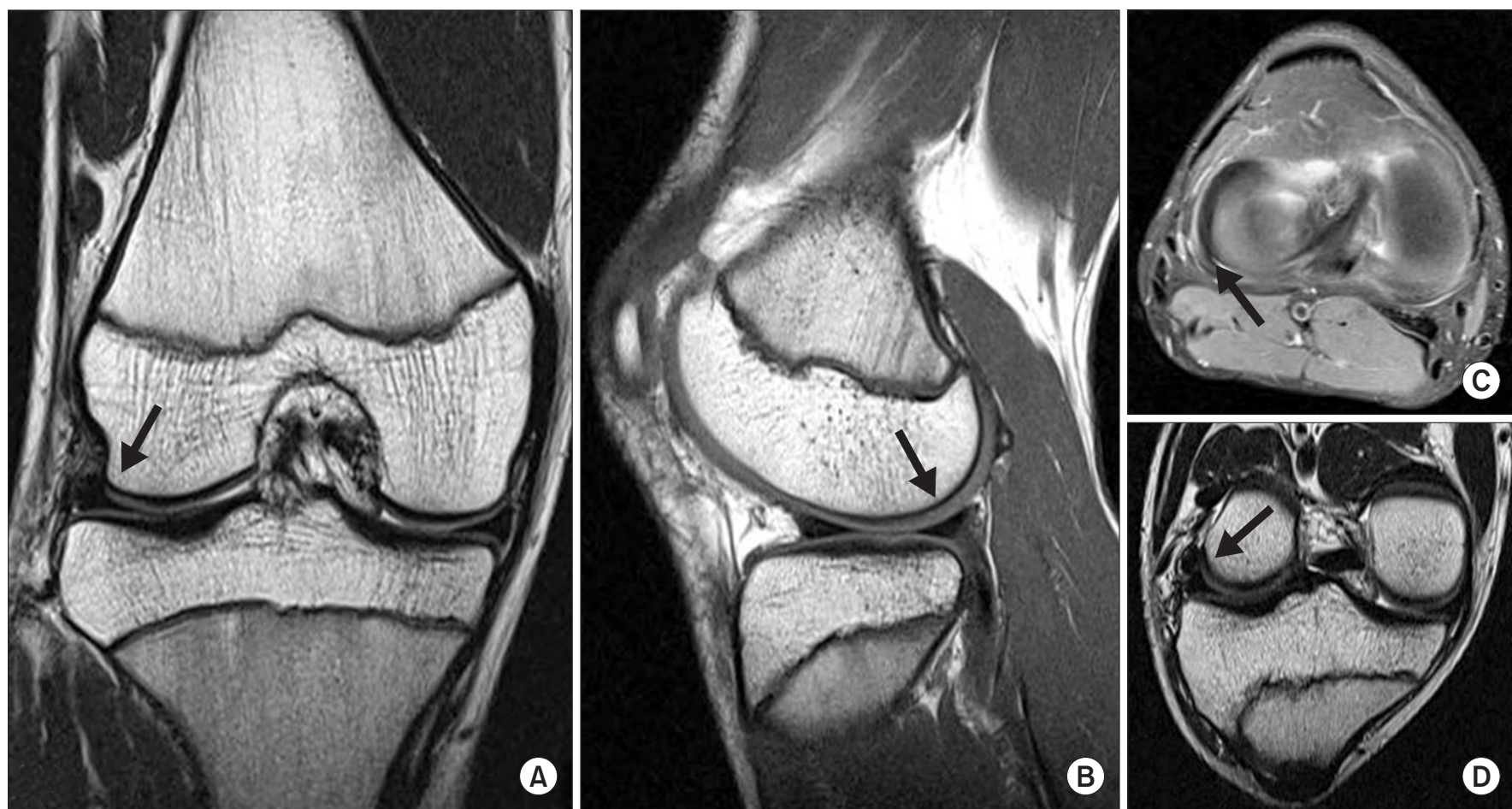

B

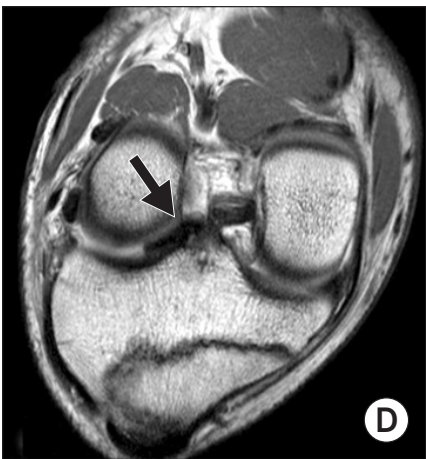

Fig. 2. Follow-up coronal (A), sagittal (B), axial (C), and oblique (D) magnetic resonance images showing reduced torn fragment with no sign of a meniscal tear (arrows). 
luxation symptoms when the knee was in full flexion to extension. He was able to return to his pre-injury level of activity. The knee examination results and function were normal. This study had institutional review board approval and informed consent was obtained from the patient's parents.

\section{Discussion}

Traumatic isolated meniscal tears can result from a twisting injury during sport activities. The incidence of bucket-handle tears of the lateral meniscus within the stable knee in adolescents has been reported as $1.7 \%{ }^{5}$. However, the true incidence of meniscal tears in children is still unknown.

The posterior segment of the lateral meniscus is relatively mobile compared with that of the medial meniscus due to its characteristic anatomy. There is various nomenclature that describes this characteristic, such as recurrent subluxation of the lateral meniscus, popliteo-meniscal fascicle tear, hypermobile posterior horn of the lateral meniscus, and MRI negative bucket handle tear of the lateral meniscus ${ }^{3,4)}$.

The healing potential of a torn meniscus depends on the location, type, length and stability: partial tears and stable vertical tears in the peripheral zone have a greater potential to heal ${ }^{6}$. Our patient had an unstable displaced bucket-handle tear of the lateral meniscus in the stable knee, which was reduced spontaneously without surgical procedure. We assume that the displaced fragment was reduced spontaneously within the week of splint application, and then healed due to high healing potential of young patients.

There are some factors that may have contributed to the healing of the meniscus in this patient: 1) the tear was in the peripheral vascular zone, that is, red-red zone, which is the location of high healing potential ${ }^{6}$; 2) the hematoma at the time of injury created a blood clot at the site of meniscal tear, providing a supply of stem cells that may have been beneficial to the healing process $^{7}$; and 3) the longitudinal tear would have left the circumferential meniscal fibers intact, exhibiting better healing potential than other types of meniscal tears. These observations support the spontaneous reduction of the displaced bucket-handle lateral meniscal tear and complete healing within 18 months from the initial injury.

In general, arthroscopic meniscal repair is a preferred treatment to prevent further injury to the meniscus and/or cartilage in the presence of unstable displaced bucket-handle tears of the lateral meniscus in children. We observed a case of isolated displaced bucket-handle tear of the lateral meniscus that spontaneously healed without surgical treatment. This is one of the few reports of spontaneous healing and further case studies are necessary to establish the prognosis of non-operative treatment of displaced bucket handle tears of the lateral meniscus.

\section{Conflict of Interest}

No potential conflict of interest relevant to this article was reported.

\section{References}

1. Thoreux P, Rety F, Nourissat G, Riviere X, Safa P, Durand S, Masquelet AC. Bucket-handle meniscal lesions: magnetic resonance imaging criteria for reparability. Arthroscopy. 2006;22:954-61.

2. Johnson MJ, Lucas GL, Dusek JK, Henning CE. Isolated arthroscopic meniscal repair: a long-term outcome study (more than 10 years). Am J Sports Med. 1999;27:44-9.

3. Ahn JH, Yim SJ, Seo YS, Ko TS, Lee JH. The double flipped meniscus sign: unusual MRI findings in bucket-handle tear of the lateral meniscus. Knee. 2014;21:129-32.

4. Ahn JH, Kim KI, Wang JH, Kyung BS, Seo MC, Lee SH. Arthroscopic repair of bucket-handle tears of the lateral meniscus. Knee Surg Sports Traumatol Arthrosc. 2015;23:205-10.

5. Terzidis IP, Christodoulou A, Ploumis A, Givissis P, Natsis K, Koimtzis M. Meniscal tear characteristics in young athletes with a stable knee: arthroscopic evaluation. Am J Sports Med. 2006;34:1170-5.

6. Weiss CB, Lundberg M, Hamberg P, DeHaven KE, Gillquist J. Non-operative treatment of meniscal tears. J Bone Joint Surg Am. 1989;71:811-22.

7. Cannon WD Jr, Vittori JM. The incidence of healing in arthroscopic meniscal repairs in anterior cruciate ligamentreconstructed knees versus stable knees. Am J Sports Med. 1992;20:176-81. 